\title{
Joint Device
}

National Cancer Institute

\section{Source}

National Cancer Institute. Joint Device. NCI Thesaurus. Code C50013.

A device designed as the junction between objects; it may be flexible or rigid. 